\title{
STRUGGLE IN FORMAL EDUCATION BY DOMESTIC-WORKER STUDENTS
}

\author{
Boj Bahadur Budhathoki ${ }^{*}$ 妮 (iD) \\ ${ }^{* 1}$ Ph.D. Scholar, Shivapuri College, Maharajganj, Nepal \\ DOI: https://doi.org/10.29121/granthaalayah.v8.i11.2020.2377
}

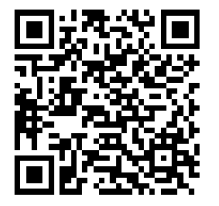

Article Type: Research Article

Article Citation: Boj Bahadur Budhathoki. (2020). STRUGGLE IN FORMAL EDUCATION BY DOMESTIC-WORKER STUDENTS. International Journal of Research GRANTHAALAYAH, 8(11), 145-152. https://doi.org/10.29121/granthaa layah.v8.i11.2020.2377

Received Date: 06 November 2020

Accepted Date: 30 November 2020

Keywords:

Domestic-Worker

Child Labor

Child Right

Child Labor Exploitation

Poverty

\section{ABSTRACT}

The various concept in education such as "Education for All (EFA)", "Equity in Education", "Inclusive Education" are the burning issues as well as implementation complexities in today's education system in developing countries. Stepping on these issues, this article focuses on seeking equity in education in the Nepalese community schools. Education for all is an ongoing process in globally. Under the national and international education framework, Nepal is on the process of implementation of the School Sector Development Program (SSDP). But, equity in education is still far behind for some groups of students. Here, this study intends to focus on, one of the similar groups of students, who are living as domestic-worker and continuing their study at the school level. This study tries to throw light on the learning-struggle of a particular group of students in Nepali community schools. The study is based on the experiences of 7 domestic-worker students (DWS) and 3 teachers teaching them. The DWS faced numerous labor exploitation problems in the workplace and school premises.

\section{INTRODUCTION}

\subsection{BACKGROUND OF THE STUDY}

In a society, everybody struggles for livelihood and there are various ways by which people try to make their living standard better. Domestic work is also not an exception. Domestic-workers are defined as the people working in the employer's house with or without a wage for the domestic chores like washing dishes, cooking, cleaning, looking after the young children, and other household activities (Gotame \& Koirala, 2009; Sharma et al., 2001). Most of the domestic-workers sell their service just for education in urban areas of Nepal and continuing their study in the Nepalese community schools in the capital city Kathmandu. The domestic workers use to be economically poor, but their main priority to work, as a domestic worker, is to achieve better and further education into an urban area. Most of the domestic workers work for their parents' choice due to poverty. Pradhan et al. (2015, pp. 23-27) claim that children, especially from marginalized and socially excluded communities, have not been able to fully enjoy their basic childhood rights including rights to education, health care, and nutrition. This results in because of economic exploitation and socio-cultural discrimination in society. Domestic work is, in fact, one of the most common forms of child employment. Many of our children are working in the pitiful conditions but we do not know how many children

(c) 2020 The Author(s). This is an open access article distributed under the terms of the Creative Commons Attribution License, which permits unrestricted use, distribution, and reproduction in any medium, provided the original author and source are credited. 
Struggle in Formal Education by Domestic-Worker Students

are involved. Nor do we know much about other characteristics of practice, such as the range of workers, what led to their employment, the terms and conditions of their work, and their feelings about it.

\section{NEPALESE SCENARIO}

Nepal is a mosaic of social diversities - it is inhabited by people of diverse social, cultural, ethnic, and religious backgrounds. The national census 2011 revealed that there are 125 castes/ethnic groups and 123 languages spoken as mother tongue in Nepal (Central Bureau of Statistics, 2014). Addressing this issue has enormous implications for the education sector to reach out to the diverse ethnic groups to provide education and literacy for all, especially concerning provisions of curriculum, textbooks, and teacher training in their mother tongues (Benson, 2004). Ministry of Education (MoE) (2016), in the SSDP document, states that to ensure the education system is inclusive and equitable in terms of access, participation, and learning outcomes, with a special focus on reducing disparities among and between groups having the lowest levels of access, participation and learning outcomes is the motto of equity in education.

The world is changing and education must change. Societies everywhere are undergoing deep transformation, and this calls for new forms of education to foster the competencies that societies and economies need, today and tomorrow (Rethinking Education, 2015, p. 3). This means moving beyond literacy and numeracy, to focus on learning environments and on new approaches to learning for greater justice, social equity, and global solidarity. Education must be about learning to live on a planet under pressure. It must be about cultural literacy, based on respect and equal dignity, helping to weave together the social, economic, and environmental dimensions of sustainable development (Rethinking Education, 2015, pp. 1-5). Education is key to the global integrated framework of sustainable development goals. Education is at the heart of our efforts both to adapt to change and to transform the world within which we live. Quality basic education is the necessary foundation for learning throughout life in a complex and rapidly changing world. Education is taken as the key to all types of developments.

Therefore, it is the major duty and responsibility of a nation to provide minimum basic level (class1-8[in Nepali Context]) education to all the citizens. Nepal is a developing country and according to the census report 2011, the literacy rate is increasing and is 65.9 percent. Most of the people of the country are living in a rural area and about $18.7 \%$ of people are living under the line of poverty (Fifteenth Plan, 2020, P. 5). The people living in rural areas are sending their children to urban areas like Kathmandu, Lalitpur, Bhaktapur, and Pokhara servicing as domesticworker and continue their studies. This group of students enrolling in the Nepalese community schools have very poor achievement and many are interrupting their study too. These students have to suffer from pitiful conditions to get a little achievement.

\section{EDUCATIONAL ACCESS}

Nepal is a multicultural, multilingual, and multiethnic society with the diverse economic ground and it is the matter of concern that education is to develop and transmit 'cultural values' that are important from the property and dignity of our society (Acharya, 2015; Sherpa, 2019). The reflection cultural activities and social potentials in the Nepalese education system are still in common practice through classroom discourse where school children are supposed to learn from their cultures - household environment, school environment, everyday activities on which students do and participate, the structure of society on which students grow, ritual festivals they celebrate, etc.

The illiteracy rate is still remarkable in the nation. To fight against illiteracy and poverty, the country has launched different national and international programs (EFA, Adult Education, Special Education, Distance Education, etc.) in the country. The quality of teachers is also enhanced through the different government based training like teachers' professional development and Tribhuvan University (TU), the largest university in the nation, is running B. Ed., One year B. Ed., M. Ed., M. Phil, and Ph.D. programs academically. But, the quality of education is still in the circle of the question, student dropping ratio is going up and equity in education is far behind. These problems are arising due to the inequality in the education structure. Nepal's multicultural society is hierarchical and divided along the lines of caste, ethnicity, and language, and its school system is categorized into different groups (Khanal, 2017). Whatever, all the students are seeking their future through education. One of those students is a domestic worker who struggles for school education during the day (10 am-4 pm) by working in other people's homes in the morning and evening. House worker-group consists of those type of students who work in others' (Rich 
Boj Bahadur Budhathoki

people) house to continue their study. This group of students is not regular in the classroom. They do not complete their home assignments in time or some of them are even not interested in doing assignments. Most of such group of students are terminating their study in the running session.

\section{THE OBJECTIVE OF THE STUDY}

The main objective of this study was concerned with to assess the DWS in different directions. If theirs' key problems would be identified, then a teacher could handle them in a better way and these groups of students benefitted to some extent. The teachers could focus on their problems and could motivate them in learning activities differently. Unstructured questions were asked to the focus group of students, which can answer mainly the following questions.

1) To investigate the working experiences of domestic-workers students.

2) To explore the problems faced by the domestic-worker students.

\section{CONDITIONS OF DOMESTIC-WORKER CHILDREN}

Child domestic work is a general reference to children's work in the domestic work sector in the home of a third party or employer. This general concept encapsulates both permissible as well as non-permissible situations (International Labour Organization (ILO) (2017). The ILO (2017) states in its report that there are many root causes of child domestic work, but in broad terms, we can differentiate between "push and pull" factors. Among the first, there are poverty and its feminization, social exclusion, lack of education, gender and ethnic discrimination, violence suffered by children in their own homes, displacement, rural-urban migration, and the loss of parents due to conflict and/or disease. That equity matters for children, teachers, and societies is indisputable. Equity is a fundamental value of public education systems, which goes beyond narrow considerations of effectiveness and efficiency. It is also a powerful policy tool in the development of quality in education (Wood, 2011). Education plays a key role in determining how you spend your adult life - a higher level of education means higher earnings, better health, and longer life (Center on Society and Health, 2015). The ILO (2017) states that "though child labor is declining at the rate of 100,000 every year, Nepal still accounts for 1.6 million children between (5-17 years) in child labor. Of these 621,000 are estimated to be engaged in hazardous work. Estimates suggest that 60 percent of children in the hazardous workplace are girls $(373,000)$ ". Child labor is a violation of the child's rights and internationally established standards. Nepal has ratified the UN's Convention on the Rights of the Child (UN CRC), the ILO convention 138 on the minimum age of employment, and the ILO convention 182 on the worst form of child labor. According to Children and Women in Social Service \& Human Rights (CWISH) (2017), child labor is a punishable crime guided by the Child Labor Prohibition and Regulation Act of 2000, together with the Labor Act 1992 and the Children's act 1992, in Nepal. Unfortunately, there is an estimated 12,265 domestic child labor (DCL) are in the service. Among them $62 \%$ are girls and $38 \%$ are boys and out of 520 domestic workers, $13 \%$ are below 14 years, $21 \%$ are 14 to 18 years and $66 \%$ are of above 18 years. $50 \%$ of the DCL are Janajati whereas 35\% are Brahmin/Chhetri and 3\% Dalits (CWISH, 2017). Among these DCLs, $96 \%$ are attending school and $4 \%$ are not attending school but $4 \%$ are on extreme domestic violence including sexual harassment (ibid).

\section{EDUCATION POLICY}

The Ministry of Education has elaborated policy directions, articulated strategies, and introduced new sets of quality led interventions for improving governance, management, and resource mobilization in school education, aiming at improving efficiency and ensuring students' learning with restructuring the school structure as Basic Level (grade 1-8) and Secondary Level (grade 9 to 12) (MoE, 2016). Moreover, the SSDP's vision to 'Contribute to the development of self-sustainable, competitive, innovative and value-oriented citizens for the socio-economic transformation of the nation,' and its mission 'to produce the needed human resources to elevate Nepal's status. The plan's goal is to contribute to socio-economic development and reduce disparities in the country through the continuous and inclusive development of its human resources capacity. The plan aims to facilitate all citizens with opportunities to become functionally literate, numerate, and to develop the basic life skills and knowledge required to enjoy a productive life, taking into account the diversity of context and needs and with regards to the forthcoming 
Struggle in Formal Education by Domestic-Worker Students

federalization of the country (MoE, 2016). According to government policy, every child has the right to an education free of cost up to basic education. The Constitution of Federal Democratic Republican Nepal (2015) has guaranteed the right to education as a fundamental right. Every child has the right to learn in his/her mother tongue and each person, society is responsible to protect the child's right to create an egalitarian society through equitable education. Furthermore, it guarantees access to basic education compulsory and free, and free education up to the secondary level.

\section{RESEARCH METHODOLOGY USED IN THE STUDY}

Research methodology is a plan, structure, procedure and strategy of investigation concerned to obtain answer to the research questions (Creswell, 2009). It is a term employed to refer to a framework for the collection and analysis of data (Bryman, 2008). Research design reflected the desire to achieve greater accuracy in measurement of social and behavioral phenomena to strengthen the social sciences by means of objective of the research (Crausz and Miller, 1974 as cited in Brewer, 2005). Research design is also a strategies plan of the project that sets out the broad structure of the research. It is necessary requirement for all research of whatever style (Brewer, 2005). In this study I followed the qualitative research design. The qualitative research used the context and setting to search for a deeper understanding of the person being studied and it is an ethnographic approach. The qualitative method of data collection was employed to capture respondents' lived experiences through their verbal and facial expressions. Qualitative data capture feelings, emotions, or subjective perceptions of something (Kabir, 2016). Qualitative methods include focus groups, group discussions, and interviews. The recorded interviews and focus group discussions were listened many times pausing in necessary sections. After gathering the field data, its transcription was the next important part of the qualitative research process for analyzing, summarizing, and thematizing.

I selected 7 house-worker students and 3 teachers teaching them to collect enough data in the process of the study from three different community schools of Kathmandu district purposively. Some of my informant students were studying in the ninth grade, who had failed the exam last year and repeating in the same class, were almost twenty years old. Among 7 students, 4 students had already passed the ninth grade in the village and again admitted in the same grade in the city. Names, studying schools, and photos of the participants were excluded in the research process to protect their ethical considerations. Whatever the names (if) used in the data collection and interpretation were only pseudonyms. Furthermore, I used semi-structured interviews with students and teachers to get crosschecked the information collected from the respective informants. To assure the quality standard of the study, I followed the prolonged engagement with participants in the field, member checking, negative case analysis, and triangulation. I claim that this research is free from personal reflexivity and biases.

During the process of interaction, I sometimes noted down the themes of the conversation and sometimes I managed to record the information. The interview was taken individually and had been taken down notes in the notebook. I recorded the interviews using audio recorder and transcribed them for the analysis. Later, I summarized the observation note and transcribed the interviews in text. Then analyses were made in descriptive and critical form so as to achieve the objectives of this study with linkage to the literature. As the process of the interpretation and analysis, I triangulated the data and tried to establish the relation of the information from different informants.

\section{DATA ANALYSIS}

Data analysis consists of examining, categorizing, tabulating, recombining the evidence obtained from the research (Baily, 2008). The accuracy of the transcription plays a role in determining the accuracy of the data that are analyzed and with what degree of dependability (Stuckey, 2014). Analysis began after reviewing the first interview to examine whether the participant was responding to the research question related to the topics or not. Qualitative data analysis was the process in which I moved from the raw data that had been collected as part of the research study and used it to provide explanations, understanding, and interpretation of the phenomena, people, and situations. The aim of analyzing qualitative data was to examine the meaningful and symbolic content of that which was found within. Typically, this was handled by identifying the participants and transcribing the data and was considered the first step in the analysis. I symbolized and used my informant DWS as P1 to P7 and teachers as T1, T2, and T3. Some of the participants expressed their lived experiences in their mother tongues which was later translated in the English language during the data transcription. 


\section{TIME MANAGEMENT OF THE DWS IN THE SCHOOL}

The students coming from the rural area and living as a domestic-worker just admit to the community school of the urban area. They spent almost all the time in the work from dawn to midnight most of the days and hardly present in the school. From the study, it was found that most of the DWS present in school for 15-20 days in a month. They do not get enough time to study in the home and irregular in school. This miserable situation of them also makes difficulty in the classroom teaching-learning activities. These students cannot understand properly what is taught in the school due to their irregularity. They also hesitate to ask teachers what is not understood. These groups of students are more laborious in their work. They struggle everywhere, in homes, at schools, even in the tiffin time too, they are busy copying the homework from their friends. In the process of personal interview, some DWS (P1, P3, and P5) expressed their similar sufferings in the oppressed tone.

I do all my homework in school in half a time. My classmates understand my problems and provide me their assignment to copy. House-owner always says every school work should finish in school, at home, you should do household works. If you don't do so, who will afford you for teaching? Moreover, I always have to miss the last class at the school because I have to reach my brother's (House owner's son) school in time to receive him. I recover missed lessons from classmates.

Some of the DWS can share their reality with their classmates and teachers easily so that they get helped from their friends understanding the ongoing problems. But, many of the DWS hid their reality among their friends due to hesitation that if the truth revealed, what would friends say to me. The DWS feared facing the truth about their life and still suffering from teachers too. In this regard, P4 expressed her experience.

I have to do all the household works from dawn to midnight. I wake up in the morning at 5 o'clock. My work begins with swiping the house, and then, preparing tea, going to shop, cooking food, and washing clothes and dishware. I always become late for school. The teacher also does not understand my problem and scolds bitterly among my classmates. This hurts me very much and I think people like me are not human. ......we are born to reject from all sides.

Nowadays, schools are considered to be cultural-friendly, student-friendly, and student central pedagogic activities are performed. In practice, it is not found as we think from outside. Students are physically and mentally tortured bitterly from some teachers. This activity in the school has helped to drop-out of school children from the school enrollment in the mid-session. Some of the DWS can no withstand the working pressure, mental and physical torture in their workplace including learning place. As a result, they terminate their study forever. However, one of the teachers (T2) put her view differently.

I encounter students from different communities, cultures, languages, cognitive levels, and interests in the same classroom. To handle, such a multicultural and diverse classroom is challenging. I use multiple pedagogic activities so that almost all the students get in the concept of related topics. I also learned at school with fear, with pressure including punishment, and without interest but today's students are studying with games, collaboration, motivation, and interaction with each other.

From the above instance, I came to know that teachers were positive towards the students and pedagogic activities were student-friendly as far as possible.

\section{HESITATION TO EXPRESS SUFFERING}

Teachers are the guardian and facilitator in the school. The future of thousands of students is on the hand of teachers. The teachers' motivation, collaborative teaching, and appropriate support to the students greatly benefit to the DWS. In some cases, teachers cannot help the students, besides, they show some rude behavior because of the students' nature. Most of the DWS and lower caste students do not express their economic, social, and personal information to their teacher in time. They use to express their reality only when something goes wrong on them scolding of teachers for frequent irregularities in the school; unable to complete the home assignment; late in class; misbehavior among classmates; missing of class test and examination; inappropriate dressing; or/and unable to upgrade. In a similar context, the next teacher (T1) added his view as "most of the students hide their conditions of suffering. They make us veil of ignorance about themselves, their reality, and their family background. Sometimes a loud voice or a light punishment is helpful to improve their bad habits like not completing the home assignment, late in the classroom, speaking a lie, fighting with friends, noising in the classes, etc. What I do in the classroom, is only to improve students' behavior and learning activities. Students' misbehaviors are harmful to themselves". The teachers claimed 
Struggle in Formal Education by Domestic-Worker Students

that whatever they did on the school premises and in the classroom was to improve their students as a whole although some students took it negatively concerning their problems. Some DWS (P3, P4, P6, and P7) had common experiences and accepted that they fully did not told about themselves what was going on them among their classmates and teachers.

There is frequently get together in our home. It is already about 11 pm as I finish dishwashing. It is usually late at night to go to bed. I can't get enough sleep. Again, I have to wake up early in the morning. If I wake up late at any morning, my work remains unfinished and I can't get a chance of going to school. I missed my school countless days of being late. My teachers and classmates always pointed me as a 'tourist' student but I never disclosed myselfamong them.

The teachers and the DWS's experiences were exactly concurrences to the point of disclosure of personal, social, and economic circumstances of students, even though they were physically and mentally explosive.

\section{POVERTY}

The DWS are likely to come from poor, often large, rural families but other factors are depending upon region, determine the likelihood of children working as domestic servants. In the context of Nepal, 18.7 percent of people are living under the poverty line and they have severe problems in feeding, lodging, and education. The families who are unable to provide education to the children, send their children working as a domestic-worker in cities seeking the children's future from education. Also, a poor family has many children rather than educated and rich families. Poverty is the major cause of child labor in Nepal and is often coupled with a lack of education. On the one hand, child labor is beneficial that enhances the child's physical, mental, spiritual, moral, and social development while on the other hand, it is destructive and exploitative. From the child worker's parent's side, it is beneficial that the child gets at least good food, environment, shelter, and opportunity of study. If the child stays at their family instead, even they cannot get this access too. In the reflection of the DWS, poverty played the major role being in the situation of what they are today. My informant P2 expressed in the weeping voice.

Our land swiped by over flooding in the village. It was very hard for my father to look after six children. There was not a quality of the school in our village, therefore, my father suggested me to go to Kathmandu for better education. It is not easy in the city too. I do not get enough learning materials and school dress in time. It took two months to buy a simple calculator.

From the above expressions of the informant, I realized that many DWS were from the rural village, concerned with the poor family, and the family's willingness was connected directly. The first reason for the children driven to the domestic-worker was poverty and the second reason was the unavailability of quality of education in the rural areas. In the interest of good education, a brighter future in life, and some earnings for family support, very young children were forced to be domestic labor in the city. House owners admitted the workers in the community schools but they did not available the necessary learning materials in time to support learning like books, copies, pens, reference books, calculators, geometry boxes, and dress. This activity was enough to downgrade the morale of students. Due to the insufficiency of learning materials, learning time at home, and frequently absent in the school, the DWS produced bad performance in the schools. Some such students were upgraded considering the problems if the teacher noticed in time but others repeated the same class year by year.

I couldn't do well in the last year. I'm in the same class this year too. This year too, teachers say that my performance is very poor. If I could not do well this year, I will stop reading. Many of my friends like me, terminated their study in the mid-session and back to their home.

The students who had no sufficient pre-knowledge to study certain topics lack sufficient time to study, less practice, and irregular in school found Mathematics, Science, and English as a harder subject. These students had suffered from more learning-struggle than others to get the same achievement. The DWS were also getting less grade than other students. Some of them got unsuccessful and even discontinued their study.

\section{VIOLENCE AND ABUSE}

The city is the center of power and privilege. It exerts its influence in charting the direction of the country's political, social, and economic development. The city, especially the capital city, has a disproportionately high share of consumption as well as investment in the urban sector. On the other hand, extreme poverty, lack of education opportunities, and the feudal legacy of employing servants in the rural areas are fueling the migration of children 
towards the urban centers (Pflug, 2002, pp. 10-13). Leaving the place of birth is a little hope and a lot of compulsion. The DWS are suffering from economic, social, physical, and mental exploitation in their workplace regularly. They cannot raise voice over the exploitation due to the fear of more exploitation. Blagbrough (2008) claims that the majority of the DWS live as well as work with their employers and they are isolated from their families and from opportunities to make friends, entertainments, and healthy foods. This means that the DWS are under the total control of employers whose primary concern is often not in their best interests as children.

.......... at home, not a single moment, my hands get rest. One day I cut my finger with pieces of glass as it broke while washing. It was bleeding and paining me, on add of that, auntie slapped me saying nothing does with sense. What a senseless bastard?

From this expression, I understood that there is severe violence on the DWS, especially girls DWS, had faced more troubles from employers' side - dis-appreciation of work, disturbing the study, scolding bitterly without any reason, speaking dirty words, overloading of works, and physical and mental torture including sexual harassments. Domestic-workers were not only abused from the employers but also the used to be physically tortured from theirs' near relatives too. My informant P6 said,

My step-mother could not stand me before her. She frequently slapped me, hair-pulled, and one day beaten by burning wood and poured hot water over me. One of my village-uncle, helped me to be here in Kathmandu. I am not good in study. I know that I will never upgrade from this class but my house owner forced me to study in school instead of directly paying for me. I do not get a single penny from my work.

The DWS were not paid for their work except lodging, foodstuff, and studying. Some of the employers admitted the DWS forcefully in community schools to be away from payment of the work. Usually, the employer showed the future of a good job and better earning, and hence continued labor exploitation of the worker.

\section{CONCLUSION}

Poverty is the biggest factor that pushed young children from rural areas to urban areas in Nepal. The lack of opportunity of good education and lack of access to earning in the rural villages are additional factors that young children were forced to be pushed on the domestic-workers on others' houses seeking a brighter future through education. The DWS were exploited physically and mentally in the workplace and school too due to a variety of reasons. Due to the hesitation of the DWS to disclose their social, economic, and personal information towards teachers and classmates, the DWS were suffering from additional problems. The DWS did not get sufficient teaching materials on time. Their guardians did not pay attention to buy the necessary materials such as books, exercise books, pens, geometry boxes, calculators, and dress for them timely as their requirement. These DWS always found themselves unfit in the classroom pedagogically. The DWS, never got the leisure time for entertainments as they had work after work at homes, and to copy the home assignments at school. Despite their hard-working, many of the DWS were unable to produce good grades in school, and some of them discontinued their schooling forever.

\section{SOURCES OF FUNDING}

This research received no specific grant from any funding agency in the public, commercial, or not-for-profit sectors.

\section{CONFLICT OF INTEREST}

The author have declared that no competing interests exist.

\section{ACKNOWLEDGMENT}

None. 


\section{REFERENCES}

[1] Acharya, B. R. (2015). Relevance of Primary Level Mathematics Education in Nepal: A Cultural Perspective, Ph.D. thesis in mathematics education, Tribhuvan University, Nepal.

[2] Baily, J. (2008). First steps in qualitative data analysis: transcribing. Family Practice. Retrieved from https://doi.org/10.1093/fampra/cmn003

[3] Benson, C. (2004). The Importance of mother tongue-based schooling for educational quality. UNESCO Digital Library. https://unesdoc.unesco.org/ark:/48223/pf0000146632

[4] Blagbrough, J. (2008). Voices of child domestic workers. Anti-slavery international.

[5] Brewer, J. D. (2005). Understanding social research. In A. Bryman (Ed.), Ethnography. Philadelphia, USA: Open University Press.

[6] Bryman, A. (2008). Social research methods (3rd ed.). New Delhi: Oxford University Press.

[7] CBS (2014). Population Monograph of Nepal Volume II. National Planning Commission Secretariat. GoN.

[8] Center on Society and Health (2015). Why Education Matters to Health: Exploring the Causes. Virginia Commonwealth University. https://societyhealth.vcu.edu/work/the-projects/why-education-matters-tohealth-exploring-the-causes.html

[9] Creswell, J. (2009). Research design, qualitative, quantitative, and mixed methods approach (3rd ed.). New Delhi: Sage Publication.

[10] CWISH (2017). Essays on Status on Child Rights in Nepal. Retrieved from https://www.cwish.org.np/publications

[11] Fifteenth plan (2020). National Planning Commission. Singha Durbar, Kathmandu. GoN.

[12] Gotame, M., \& Koirala, H. L. (2001). Domestic Working as Gendered Space: A Study of Selected Localities in Kathmandu. The Geographical Journal of Nepal, 7, 23-32

[13] ILO (2017). Child Labour and Domestic Work. Retrieved from https://www.ilo.org/ipec/areas/Childdomesticlabour/lang--en/index.htm

[14] Kabir, S. M. S. (2016). Methods of Data Collection. Retrieved from https://www.researchgate.net/publication/325846997

[15] Khanal, P. (2017). Falling prey to the dominant culture? Demystifying symbolic violence against ethnic minority students in Nepal. Pedagogy, Culture and Society, 25(3), 457-467. https://doi.org/10.1080/14681366.2017.1280841

[16] MoE (2016). School Sector Development Plan, Nepal, 2016-2023. Kathmandu: Ministry of Education, Government of Nepal.

[17] Pflug, B. (2002). An Overview of Child Domestic Worker in Asia. Retrieved from www.ilo.org

[18] Pradhan, G., Tuladhar, I., \& Thakuri, S., (2015). Towards Brighter Future for Nepal: A Situation Analysis of Child Rights in Nepal. Royal Norwegian Embassy

[19] Rethinking Education (2015). France: UNESCO Publishing.

[20] Sharma, S., Thakurathi, M., Sapkota, K., Devkota, B., \& Rimal, B. (2001). Situation of Domestic Child Labourers in Kathmandu: A Rapid Assessment. Kathmandu: ILO-IPEC.

[21] Sherpa, D. (2019). Exploring the Dimensions of Multicultural Education and its Implication in Teaching Learning. Interdisciplinary Research in Education, 4(1), 35-42.

[22] Stuckey, H. L. (2014). The First Step in Data Analysis: Transcribing and Managing Qualitative Research Data. Journal of Social Health and Diabetes, 2(1), 6-8. doi: 10.4103/2321-0656.120254

[23] The constitution of Nepal (2015). Constituent Assembly Secretariat. Singha Durbar, Kathmandu. 